\title{
Pemasaran digital dengan memanfaatkan landing page pada perusahaan start-up
}

\author{
Angga Febrian ${ }^{1 *}$, Lia Febria Lina ${ }^{2}$, Vera Apri Dina Safitri ${ }^{3}$, Agus Mulyanto $^{4}$
}

1 Universitas Teknokrat Indonesia, Bandar Lampung, Indonesia, email: Angga_febrian@teknokrat.ac.id 2Universitas Teknokrat Indonesia, Bandar Lampung, Indonesia, email: Liafebrialina@teknokrat.ac.id

3Universitas Teknokrat Indonesia, Bandar Lampung, Indonesia, email:Vera.Apridinasafitri@teknokrat.ac.id ${ }^{4}$ Universitas Teknokrat Indonesia, Bandar Lampung, Indonesia, email:Agus.mulyanto@teknokrat.ac.id

*Koresponden penulis

\section{Info Artikel}

Diajukan: 05 Feb 2021

Diterima: 06 Jul 2021

Diterbitkan: 13 Jul 2021

Keywords:

social media; landing page; marketing; start up

Kata Kunci:

media sosial; landing page; pemasaran; start up

\section{Lisensi:}

cc-by-sa

\begin{abstract}
The increasing use of social media such as Instagram and Facebook can be utilized to reach a wider and more targeted consumer by creating the right content organically (free of charge), and doing paid advertising on these platforms. However, his lack of knowledge about how to make real content and paid advertising is an obstacle for marketers to take advantage of it. So that we need the right strategy in marketing products through these media. The marketer's job is to increase the number of followers on social media and customer interactions because there is a positive relationship between the number of followers and sales. This training aims to help startups in Lampung to maximize the use of social media, in this case, we provide training in creating landing pages and financial preparation training. Partners in this activity are sharia motorcycle taxi transportation companies (OJESA). In the end, this activity can be beneficial for partners by increasing knowledge about digital marketing by utilizing landing pages in advertising and managing finances. Partners can use the facilities provided by the platform in advertising. As well as understanding effective and efficient advertising tactics and strategies.
\end{abstract}

\section{Abstrak}

Penggunaan media sosial seperti Instagram dan Facebook yang semakin meningkat, dapat dimanfaatkan dalam menjangkau konsumen yang lebih luas dan tertarget dengan cara membuat konten yang tepat secara organik (tidak berbayar), dan melakukan iklan secara berbayar pada platform tersebut. Namun, minimnya pengetahuan tentang cara membuat konten yang benar dan mengelola iklan yang berbayar, menjadi hambatan bagi pemasar dalam memanfaatkannya. Sehingga diperlukan strategi yang tepat dalam memasarkan produk melalui media tersebut. Tugas pemasar adalah meningkatkan jumlah pengikut pada media sosial dan keterlibatan pelanggan, karena terdapat hubungan yang positif antara jumlah pengikut dengan penjualan. Pelatihan ini bertujuan membantu startup yang ada di Lampung untuk dapat memaksimalkan penggunaan media sosial, dalam hal ini kami memberikan pelatihan dalam membuat landing page dan pelatihan penyusunan keuangan. Mitra dalam kegiatan ini adalah perusahaan transportasi ojek syariah (OJESA). Pada akhirnya, kegiatan ini dapat bermanfaat bagi mitra dengan bertambahnya pengetahuan tentang pemasaran digital dengan memanfaatkan landing page dalam beriklan dan pengelolaan keuangan. Mitra dapat menggunakan fasilitas yang disediakan oleh 


\section{PENDAHULUAN}

Perkembangan teknologi dan internet membawa perubahan pada berbagai aspek. Salah satunya merubah cara komunikasi masyarakat. Jika sebelumnya komunikasi dan interaksi dilakukan secara tradisional seperti bertatap muka secara langsung kini dapat dilakukan dengan menggunakan berbagai aplikasi online dan juga berbagai media sosial seperti Facebook, Instagram dan Twitter. Hal ini terbukti jika dilihat dari data pengguna internet di Indonesia pada awal tahun 2021 ini mencapai 202,6 juta jiwa. Jumlah ini meningkat 15,5 persen atau 27 juta jiwa jika dibandingkan tahun sebelumnya 2020 (Riyanto, 2021). Melihat data tersebut menjadi sebuah peluang bagi pemasar untuk dapat memanfaatkan media sosial sebagai media pemasaran. Pemasaran media sosial diartikan sebagai pemasaran yang dilakukan dengan menggunakan media sosial untuk mencapai organisasi dengan menciptakan nilai bagi pemangku kepentingan (Felix et al., 2016; Goyal et al., 2018).

Media sosial memengaruhi cara pemasar dalam menghubungkan antara konsumen dengan merek dan produk serta media sosial akan memiliki dampak besar pada budaya konsumsi masyarakat (Sheth, 2018). Seperti yang dilakukan oleh perusahaan e-commerce di Indonesia yang memanfaatkan media sosial dalam menarik minat konsumen untuk membeli produk di website (Febrian \& Fadly, 2021). Mengingat pentingnya peran media sosial dalam pemasaran, diperlukan strategi yang tepat dalam memasarkan produk melalui media tersebut. Bagaimana pemasar dapat meningkatkan jumlah pengikut pada media sosial, karena terdapat hubungan yang positif antara jumlah follower dan penjualan, walaupun secara tidak langsung dapat meningkatkan penjualan, tetapi dengan banyaknya jumlah pengikut dapat meningkatkan pengambilan sampel karaketristik pelanggan dan komentar pada produk yang dipromosikan dan pada akhirnya memengaruhi penjualan (Saboo et al., 2015). Melakukan like atau memberikan komentar dalam media sosial perusahaan dianggap sebagai salah satu bentuk engagement pengguna pada perusahaan. Brand engagement adalah tingkatan suatu motivasi pelanggan individu, terkait merek dan tergantung konteks dari pikiran yang ditandai oleh level spesifik dari aktivitas kognitif, emosional dan perilaku dalam melakukan interaksi langsung dengan perusahaan (Hollebeek, 2011). Barger, Peltier, \& Schultz (2016) juga telah mengoperasionalkan keterikatan konsumen sebagai serangkaian tindakan terukur yang dilakukan konsumen di media sosial sebagai tanggapan terkait dengan konten yang ditampilkan sebuah merek di media sosial seperti bereaksi terhadap konten seperti menekan hati, memberi peringkat atau bintang, mengomentari konten, berbagi konten dengan orang lain dan memposting konten buatan pengguna seperti ulasan konsumen di berbagai media sosial baik Facebook maupun Twitter.

Brand engagement pada media sosial juga dianggap sebagai salah satu hal penting bagi perusahaan untuk mendapatkan keunggulan kompetitif dan membantu produk atau merek dapat lebih dikenal dan selalu diingat oleh 
konsumen, bahkan dapat berdampak kepada peningkatan penjualan (Gómez, Lopez, \& Molina, 2019; Rohadian \& Amir, 2019). Sehingga, peningkatan ketertarikan menjadi sangat penting dalam konteks bisnis pada saat ini. Oleh karena itu kegiatan Pengabdian ini berfokus pada peningkatan brand engagement pada media sosial dengan menggunakan landing page pada Startup di Lampung yaitu Ojek Syariah atau yang disebut dengan OJESA. OJESA merupakan layanan jasa transportasi khusus wanita, dengan tujuan mewujudkan transportasi yang ramah anak dan wanita di Indonesia dan mampu memberdayakan para wanita. Berdasarkan wawancara singkat, terdapat kelebihan OJESA yaitu memiliki 300 mitra yang tersebar di 4 wilayah Indonesia yaitu Bandar Lampung, Metro, Palembang dan Suka Bumi. Ojesa memiliki keunggulan yang lebih dibanding dengan perusahaan serupa, seperti lebih memprioritaskan driver dan customernya adalah anak-anak dan wanita hal ini dilatarbelakangi oleh berbagai kasus driver online yang tidak memberikan kenyamanan pada konsumen wanita.

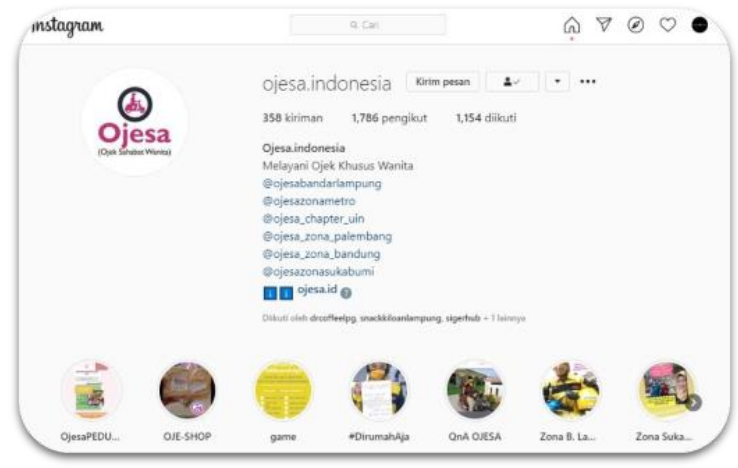

Gambar 1. Instagram OJESA

Namun, kami juga menemukan berbagai permasalahan yang dialami mitra yaitu belum dapat memaksimalkan pemasaran online melalui media sosial untuk menjangkau konsumen dan meningkatkan brand engagement yang pada akhirnya memiliki implikasi pada peningkatan penjualan. Hal tersebut dilakukan dengan tujuan pembentukkan keterikatan merek yang dapat mendorong kinerja, baik dari sisi keuangan maupun dari sisi non keuangan seperti peningkatan jumlah kunjungan dan interaksi di media sosial dan website. Hal ini dapat dilihat dari laman media sosial mitra dimana jumlah pengikut dan juga interaksi masih rendah.

\section{METODE PELAKSANAAN}

Pelaksanaan kegiatan di lakukan pada tanggal 6 Oktober 2020 di Warung Upnormal Kota Bandar Lampung. Kegiatan diikuti oleh tim dari Ojesa. Untuk mengatasi masalah pada mitra, maka diperlukan adanya sharing knowledge dalam memaksimalkan media digital untuk mempromosikan produk baik melalui media sosial yang sudah ada, kegiatan ini terbagi menjadi 3 bagian yang dipaparkan sebagai berikut. 
1. Perkenalan

Dengan maksud untuk menyampaikan tujuan kegiatan serta berdiskusi permasalahan mitra.

2. Pelatihan

- Menjelaskan langkah-langkah yang dapat diterapkan seperti memaksimalkan Facebook ads, Instagram ads.

- Penggunaan Landing page dengan baik agar pelanggan membangun minat mereka dalam memilih produk (DuPont et al., 2018).

- Memberikan solusi permasalahan, pelatihan dan pendampingan maksimalisasi media digital seperti memaksimalkan Facebook ads, Instagram ads yang sudah tersedia pada layanan platform yang dimiliki mitra.

3. Pendampingan pembuatan Landing Page

Membantu mitra untuk membuat Landing Page lebih menarik dan membantu mitra memahami dan dapat menggunakan landing page dalam menunjang kegiatan iklan. Landing page sangat berperan penting dalam dunia pemasaran masa kini, karena ketika pemasar dapat mengembangkan landing page dengan baik pelanggan akan membangun minat mereka dalam memilih produk (DuPont et al., 2018).

\section{HASIL DAN PEMBAHASAN}

Kegiatan dilakukan dengan memberikan pengetahuan secara teori dan praktik dalam bidang pemasaran, keuangan dan teknologi. Melalui tim PKM yang dijelaskan pada tabel 2. dalam berbagi tugas sesuai kepakaran masingmasing tim. Sehingga mitra tidak hanya mampu memahami dalam satu bidang, namun mencakup semua proses bisnis yang dijalankan agar lebih baik. Mitra juga dilatih untuk membuat landingpage secara mandiri, sehingga kedepannya dapat mandiri dan menyesuaikan konten pemasaran sesuai kebutuhan. Landing page dapat mendorong pengguna internet untuk fokus pada suatu produk dan cepat dapat mengambil aksi dalam website seperti mengunjungi media sosial, membeli produk atau menjelajah informasi lanjutan. Landingpage tersebut menjadi suatu hal yang wajib dipahami dalam periklanan di pemasaran digital, sehingga tampilan dan copywriting sangat penting dipahami. Berikut adalah uraian tugas tim penulis dalam pelaksanaan kegiatan PKM.

Tabel 1. Uraian tugas Tim PKM

\begin{tabular}{|c|c|c|}
\hline No. & Nama & Deskripsi Tugas \\
\hline 1 & Angga Febrian & $\begin{array}{l}\text { Memberikan pelatihan untuk memaksimalkan media digital } \\
\text { termasuk Facebook ads dan Instagram ads }\end{array}$ \\
\hline 2 & Agus Mulyanto & $\begin{array}{l}\text { Membuat landing page dan bertanggung jawab untuk mendampingi } \\
\text { mitra untuk memaksimalkan landing page }\end{array}$ \\
\hline 3 & Lia Febria Lina & $\begin{array}{l}\text { Memberikan pelatihan untuk memaksimalkan media digital dengan } \\
\text { manajemen komunikasi digital dan maksimalisasi konten untuk } \\
\text { meningkatkan ketertarikan merek. }\end{array}$ \\
\hline 4 & Vera Apridina & Pelatihan untuk pengelolaan keuangan Startup \\
\hline
\end{tabular}


Berikut adalah dokumentasi kegiatan ketika pemaparan materi oleh pembicara:

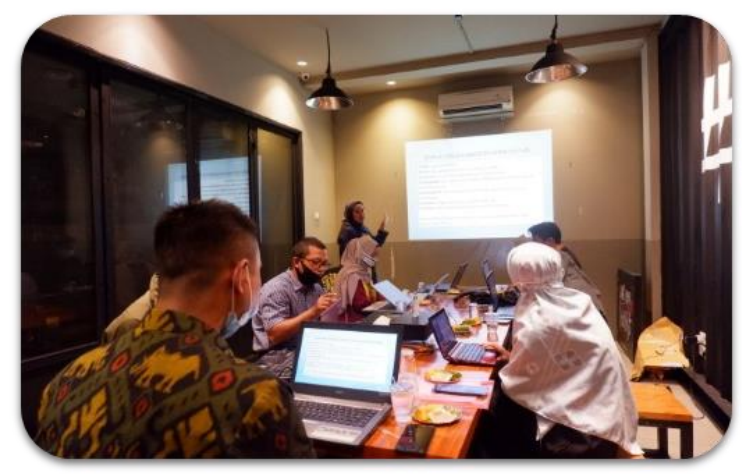

Gambar 2. Materi tentang pemanfaatan konten media sosial

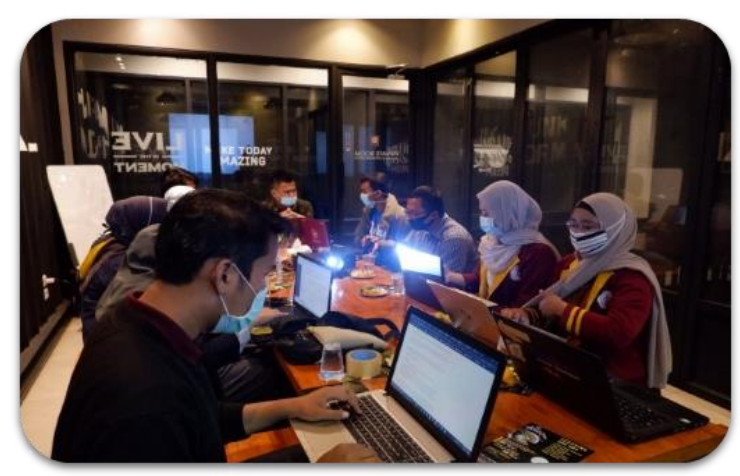

Gambar 3. Penyampaian materi landing page ke dalam Facebook ads

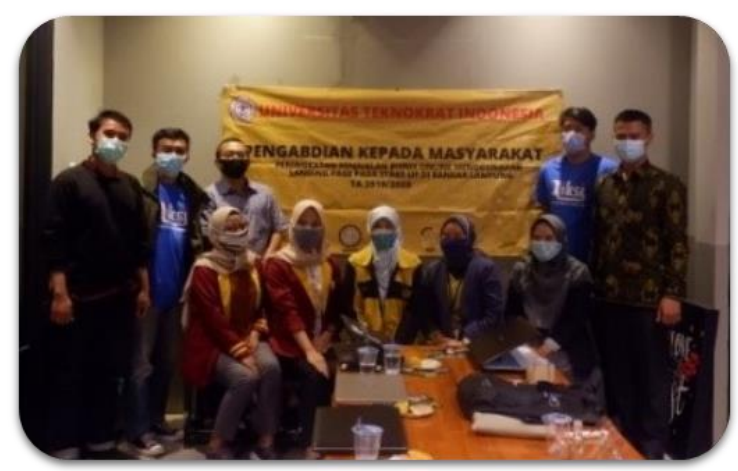

Gambar 4. Foto bersama tim pengabdian dengan mitra Ojesa

Manfaat yang diperoleh dari kegiatan ini jika dilihat dari sisi ekonomi dan sosial, mitra dapat meningkatkan pemahaman tentang bagaimana mengelola media digital untuk membangun komunikasi kepada target konsumennya. Selain itu, pemahaman tentang bagaimana jumlah pengikut pada media sosial memiliki pengaruh yang positif pada penjualan atau penggunaan jasa yang mereka miliki. Meski membutuhkan waktu yang tidak cepat, namun proses ini 
dapat meningkatkan pengambilan sampel karaketristik pelanggan dan komentar pada produk yang dipromosikan dan digunakan untuk perusahaan dalam riset dan memperbaiki kualitas sehingga kedepannya dalam meningkatkan penjualan. Kegiatan PKM ini sudah membantu startup dalam meningkatkan pemanfaatan media sosial dan engagement rate, hal ini dapat dilakukan dengan memiliki landing page dan pemahaman mitra dalam membuat iklan di media sosial secara efektif dan efesien. Gambar 5 menampilkan bentuk landingpage yang dibuat dengan berbagai informasi yang menampilkan keunggulan yang menarik bagi konsumen. Terdapat beberapa bagian halaman yang ditampilkan pada landingpage tersebut, diawali dengan headline, keunggulan produk, video profil mitra, testimoni konsumen dan call to action berupa tombol Whatsapp yang memudahkan pelanggan dalam menghubungi OJESA.

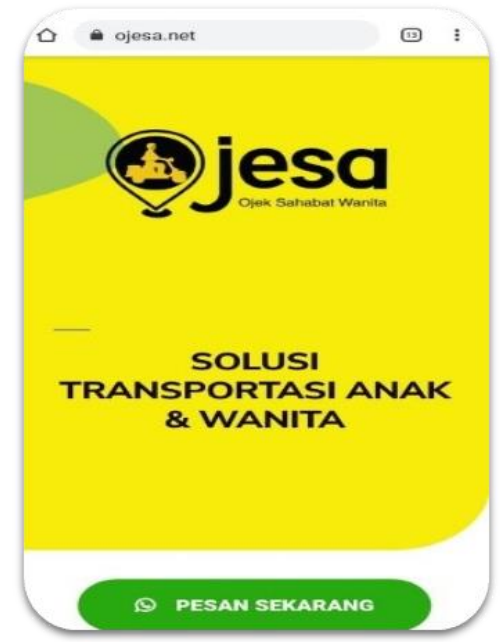

Gambar 5. Landing page OJESA

Tautan website tersebut dapat di akses melalui http://ojesa.net yang di manfaatkan ketika beriklan di media sosial seperti Facebook ads dan Instagram ads. Mengingat salah satu syarat pemilik akun untuk dapat beriklan di media sosial adalah sudah memiliki website. Setelah memiliki website maka langkah selanjutnya adalah menggunakannya di media sosial, karena terdapat pengaturan yang harus di kelola dengan benar di bagian admin user Facebook. Kelebihan memasarkan di media sosial adalah kita dapat menentukan target dari siapa yang akan menerima materi iklan yang kita buat. Mulai dari umur, lokasi, dan ketertarikan terhadap sesuatu yang direkam oleh Facebook. Sehingga kita dapat lebih menjangkau pelanggan sesuai dengan segmentasi produk.

Untuk mensosialisasikan kegiatan ini kepada masyarakat, tim PKM sudah menyiarkannya melalui Youtube dan media massa online (Lampung, 2020). Hal tersebut dilakukan agar masyarakat juga mengetahui pentingnya kemampuan dalam memaksimalkan media sosial dalam memasarkan produknya. 


\section{KESIMPULAN}

Kegiatan ini bertujuan untuk membantu para mitra dalam melakukan pemasaran digital melalui pemanfaatan landing page di media sosial dengan beberapa pelatihan yang diberikan. Selain pengetahuan dan keterampilan tentang pemasaran digital, mitra juga diberikan pelatihan tentang manajemen keuangan agar para mitra dapat mengelola keuangan bisnisnya dengan baik. Proses yang baik dilakukan selama kegiatan dengan keterlibatan aktif mitra. Terdapat beberapa indikator pencapaian yang menjadi keberhasilan kegiatan ini yaitu, kemampuan mitra dalam membuat landing page dengan mandiri serta memahami penerapannya di beberapa media iklan online Facebook ads, dan Instagram ads. Penggunaan iklan online menjadi sebuah keharusan bagi pelaku bisnis untuk dapat menjangkau lebih luas pelanggannya. Pemanfaatan media sosial seperti Facebook dan Instagram juga dapat dimaksimalkan dalam membentuk citra merek bisnis. Kegiatan ini tentu saja masih terdapat kekurangan, salah satunya adalah hanya memberikan pelatihan kepada mitra yang terbatas. Maka, sangat disarankan untuk melakukan kegiatan serupa dengan target mitra yang lebih luas terutama UMKM agar dapat meningkatkan kinerja, baik kinerja pemasaran dan kinerja keuangan.

\section{UCAPAN TERIMA KASIH}

Terima kasih untuk Universitas Teknokrat Indonesia yang sudah mendukung kegiatan ini sampai terlaksana dengan baik.

\section{DAFTAR RUJUKAN}

Barger, V., Peltier, J. W., \& Schultz, D. E. (2016). Social media and consumer engagement: a review and research agenda. Journal of Research in Interactive Marketing, 10(4), 268-287. https://doi.org/10.1108/JRIM-062016-0065

DuPont, J., Harff, S., Park, S., \& Linder, K. E. (2018). Marketing Online Degrees to Adult Learners: Staff, Resources, and Key Strategies. Leading and Managing E-Learning, 321-334. https://doi.org/10.1007/978-3-31961780-0_22

Febrian, A., \& Fadly, M. (2021). The Impact of Customer Satisfaction with Implications for EWOM and Brand Equity on E-Commerce Purchase Intention in Indonesia. Binus Business Review, 12(1), xx-xx. https://doi.org/10.21512/bbr.v12i1.6419

Felix, R., Rauschnabel, P. A., \& Hinsch, C. (2016). Elements of strategic social media marketing: A holistic framework. Journal of Business Research, 70, 118-126. https://doi.org/10.1016/j.jbusres.2016.05.001

Gómez, M., Lopez, C., \& Molina, A. (2019). An integrated model of social media brand engagement. Computers in Human Behavior, 96(January), 196206. https://doi.org/10.1016/j.chb.2019.01.026

Goyal, N., Bron, M., Lalmas, M., Haines, A., \& Cramer, H. (2018). Designing for mobile experience beyond the native ad click: Exploring landing page presentation style and media usage. Journal of the Association for Information Science and Technology, 69(7), 913-923. 
https://doi.org/10.1002/asi.24016

Hollebeek, L. D. (2011). Demystifying customer brand engagement: Exploring the loyalty nexus. Journal of Marketing Management, 27(7-8), 785-807. https://doi.org/10.1080/0267257X.2010.500132

Lampung, K. (2020). PKM FEB UTI Beri Pelatihan Keuangan dan Pemasaran Kepada Penggiat Start Up di Lampung.

Riyanto, G. P. (2021). Jumlah Pengguna Internet Indonesia 2021 Tembus 202 Juta. In Kompas.com (Reska K. N). Kompas. https://tekno.kompas.com/read/2021/02/23/16100057/jumlahpengguna-internet-indonesia-2021-tembus-202-juta

Rohadian, S., \& Amir, M. T. (2019). Upaya Membangun Customer Engagement Melalui Media Sosial Instagram (Studi kasus : online shop yang menjual produknya sendiri). Journal of Entrepreneurship, Management, and Industry (JEMI), 2(4), 179-186. http://journal.bakrie.ac.id/index.php/JEMl/article/view/1925

Saboo, A. R., Kumar, V., \& Ramani, G. (2015). Evaluating the impact of social media activities on human brand sales. International Journal of Research in Marketing, 33(3), 524-541. https://doi.org/10.1016/j.jiresmar.2015.02.007

Sheth, J. N. (2018). How social media will impact marketing media. Social Media Marketing: Emerging Concepts and Applications, 3-18. https://doi.org/10.1007/978-981-10-5323-8_1 